\title{
NEITHER WORKER, NOR QUEEN: AN ANT CASTE SPECIALIZED IN THE PRODUCTION OF UNFERTILIZED EGGS
}

\author{
By J. HeINZE ${ }^{1,2}$, S.P. COVER $^{3}$, AND B. HÖLLDOBLER ${ }^{2}$
}

\begin{abstract}
In addition to a queen and workers, colonies of the ant Crematogaster smithi Creighton from Chiricahua Mountains, Arizona, may contain one or several conspicuous "large workers," whose size, external morphology, and number of ovarioles are intermediate between that of queens on one side and that of workers on the other. According to laboratory observations, "large workers" are specialized for the production of unfertilized eggs, which are mainly eaten by the larvae and the queen but may develop into males in queenless colonies. We describe the morphology and the behavior of "large workers" and discuss their evolutionary significance.
\end{abstract}

\section{INTRODUCTION}

The societies of ants, bees, and many wasps are characterized by reproductive division of labor between two major female castes: the queens, which specialize in reproduction, and the workers, which attend to foraging, brood care, defense, and nest maintenance. In addition, in some ant species morphologically different worker castes occur, which perform particular tasks. For example, larger workers may guard the nest entrance, mill seeds, or serve as storage tanks of liquid food (Wilson, 1971; Hölldobler and Wilson, 1990). The ovaries of ant workers are typically less developed than those of the queens and in most species lack a spermatheca for the storage of sperm. Nevertheless, the workers of many species are

\footnotetext{
${ }^{1}$ Present address: Zool. Inst. I, Univ. Erlangen-Nürnberg, Staudtstrasse 5, D-91058 Erlangen, Germany

${ }^{2}$ Theodor-Boveri-Institut (Biozentrum), Lehrstuhl Verhaltensphysiologie and Soziobiologie, D-97074 Würzburg, Germany

${ }^{3}$ Museum of Comparative Zoology, Harvard University, Cambridge, MA 02138, USA
}

Manuscript received 22 November 1995. 
capable of laying unfertilized eggs. These eggs may be eaten by adult nestmates or larvae (e.g., Torossian, 1978; Crespi, 1992) or may develop into haploid males (Bourke, 1988a; Choe, 1988). Whether or not workers lay eggs, and which individuals do so, is typically determined by various factors, such as the absence or presence of a queen (e.g., Bier, 1954; Dejean and Passera, 1974; Passera, 1980; Hölldobler and Wilson, 1983), worker age (Wilson, 1985; Bourke, 1988a; but see Sendova-Franks and Franks, 1993) or rank in a dominance hierarchy (Cole, 1981; Franks and Scovell, 1983; Bourke, 1988b; Oliveira and Hölldobler, 1990; Peeters and Tsuji, 1993, Heinze, Hölldobler, and Peeters, 1994).

Workers of the widely distributed myrmicine genus Crematogaster are typically monomorphic and small to medium in size. Egg-laying and male production by workers have been documented in several species, and Soulié (1970) claimed that in C. scutellaris, workers produce diploid offspring by thelytokous parthenogenesis. Here we report on the occurrence of a female caste in the ant $\mathrm{Cre}$ matogaster (Orthocrema) smithi Creighton (considered a subspecies of C. minutissima Mayr in Creighton, 1950), which appears to be morphologically and functionally specialized for the production of unfertilized eggs. This discovery adds a new facet to the division of labor in social insects.

\section{Material AND Methods}

Colonies of C. smithi Creighton were collected from their soilnests in summers 1992 and 1993 and spring 1996 near Portal, Cochise Co., Arizona. Most colonies were censused immediately after collecting and transferred first into petri dishes with moist cotton and later into perspex boxes with a plaster floor. In the laboratory, the ants were kept at $25^{\circ} \mathrm{C}$ and fed three times per week with diluted honey and pieces of cockroaches or crickets.

Behavior was observed either directly under a binocular microscope or by video-taping using a Panasonic AG 6720A time lapse video recorder, a Panasonic F15 camera and a $105 \mathrm{~mm}$ Nikkor macro-lens. To examine ovarian development, ants were killed by freezing and dissected with forceps by gently pulling the subgenital plate with the attached sting apparatus and ovaries out of the gaster. In some cases it was necessary to completely dissect the 
gaster, as elongated ovaries with mature oocytes tended to fracture when the subgenital plate was extracted.

Voucher specimens are deposited in the Museum of Comparative Zoology at Harvard University (Cambridge, Mass.).

\section{RESULTS}

Composition of field colonies

A total of 42 colonies and three additional solitary founding queens were excavated at two sites in the Chiricahua Mountains in southeastern Arizona. The ants nested in juniper-oak-pinyon forests $3 \mathrm{~km}$ west of the Southwestern Research Station on National Forest Road 42 and $1 \mathrm{~km}$ north of Herb Martyr on the Greenhouse Trail, respectively, both sites at an elevation of approx. $2000 \mathrm{~m}$. Nests were discovered by turning flat rocks and removing leaf litter. Numerous workers and brood were found directly under the rock or litter surface, but nest chambers reached into the rocky soil down to $40 \mathrm{~cm}$ and more. The queen and the "large workers" were found at intermediate depths.

Colonies contained a single queen (which was not found in some cases), 33-450 workers $(\mathrm{n}=18$, arithmetic mean $=272 \pm \mathrm{SD}$ 129), and brood. Colonies collected in August 1992 contained female and male sexual adults or pupae. In August 1993, the lack of sexuals in colonies and the finding of three solitary founding queens suggested that mating flights had already occurred. In 23 of 42 colonies (17 queenright), one or more "large workers" were found (arithmetic mean $=2.5 \pm \mathrm{SD} 2.2$; median 2, range $=1-10$ ). Colonies containing "large workers" did not differ in size from those lacking them (Mann-Whitney U-test, $\mathrm{U}=8, \mathrm{p}=0.2$ ).

Morphology of "large workers"

"Large workers" were intermediate in size and morphology between queens and normal workers. This was most visible in the alitrunk where "large workers" exhibited a range of structure consistently more complex and queen-like than that of ordinary workers (Table 1, Fig. 1). Furthermore, "large workers" had pigmented spots in the site of wings, and at least feeble impressions in the site of ocelli. "Large workers" also had an intermediate number of ovarioles (Table 1). The ovaries of small workers and "large workers" always lacked a spermatheca. 
Table 1. Size, weight, ovariole number, and fecundity of the three female castes in the ant, Crematogaster smithi. The various parameters could not be examined in all specimens. The number of individuals examined ranged between 10 and 100 (workers), 8 and 12 ("large workers"), and 3 and 10 (queens).

Egg laying data are from colonies which were transferred from the field into the laboratory on the first day of the experiment ("field") or from colonies which had been kept in the laboratory for at least two months ("laboratory").

\begin{tabular}{lccc}
\hline & small worker & "large worker" & queen \\
\hline head width [mm] & $0.59 \pm 0.032$ & $0.82 \pm 0.030$ & $0.93 \pm 0.030$ \\
alitrunk length [mm] & $0.65 \pm 0.037$ & $1.03 \pm 0.055$ & $1.94 \pm 0.091$ \\
pronotal width [mm] & $0.39 \pm 0.021$ & $0.55 \pm 0.024$ & $0.95 \pm 0.055$ \\
life weight [mg] & $0.72 \pm 0.170$ & $2.2 \pm 0.37$ & $5.3 \pm 1.44$ \\
ovariole number & $2.0 \pm 0.00$ & $10.2 \pm 1.99$ & $21.2 \pm 2.40$ \\
eggs laid in 3 days (laboratory) & $0.1 \pm 0.10$ & $6.4 \pm 6.77$ & $33.0 \pm 13.71$ \\
eggs/mg/day (laboratory) & 0.05 & 0.97 & 2.1 \\
eggs laid in 3 days (field) & $?$ & $2.9 \pm 2.8$ & $22.6 \pm 2.61$. \\
\hline
\end{tabular}

Behavior of "large workers"

Nothing is known about the behavior of $C$. smithi in the field. We therefore attempted to uncover the role of "large workers" in a series of experimental manipulations and more than 120 hours of direct and time-lapse video observations in the laboratory. The "large workers" neither foraged nor engaged in prolonged brood care, and generally behaved in a manner very similar to the queen, i.e., they moved slowly about the nest, sat on the brood pile, and were intensively groomed by workers (Table 2). In queenless and to a lesser extent also in queenright colonies, the "large workers" were surrounded by a court of small workers, as were the queens in other colonies. Both queens and "large workers" regularly opened their mandibles to small workers as if offering food, but when they were fed with an amaranth-honey mixture no transfer of the stained crop content to the small workers, easily visible through the translucent cuticle, could be detected. These "food offering" rates did not increase when isolated "large workers" were fed with honey and returned into starved colonies (acts/hr: non-starved colonies, $\mathrm{n}=4, \mathrm{x}=0.3 \pm$ SD 0.1, starved colonies, $\mathrm{n}=3, \mathrm{x}=0.2 \pm$ 0.4 ; two-tailed Mann-Whitney U-test, $\mathrm{U}=4, \mathrm{p}>0.1$ ). Similarly, the mortality rates from starvation did not differ significantly between groups of 24 small workers and a "large worker" and groups of 25 small workers, all similarly deprived of food (average survival period of small workers in days: without "large worker," $\mathrm{n}=10,4.2 \pm$ SD 2.0; with "larger worker," $\mathrm{n}=10,3.6 \pm \mathrm{SD} 1.1$; 


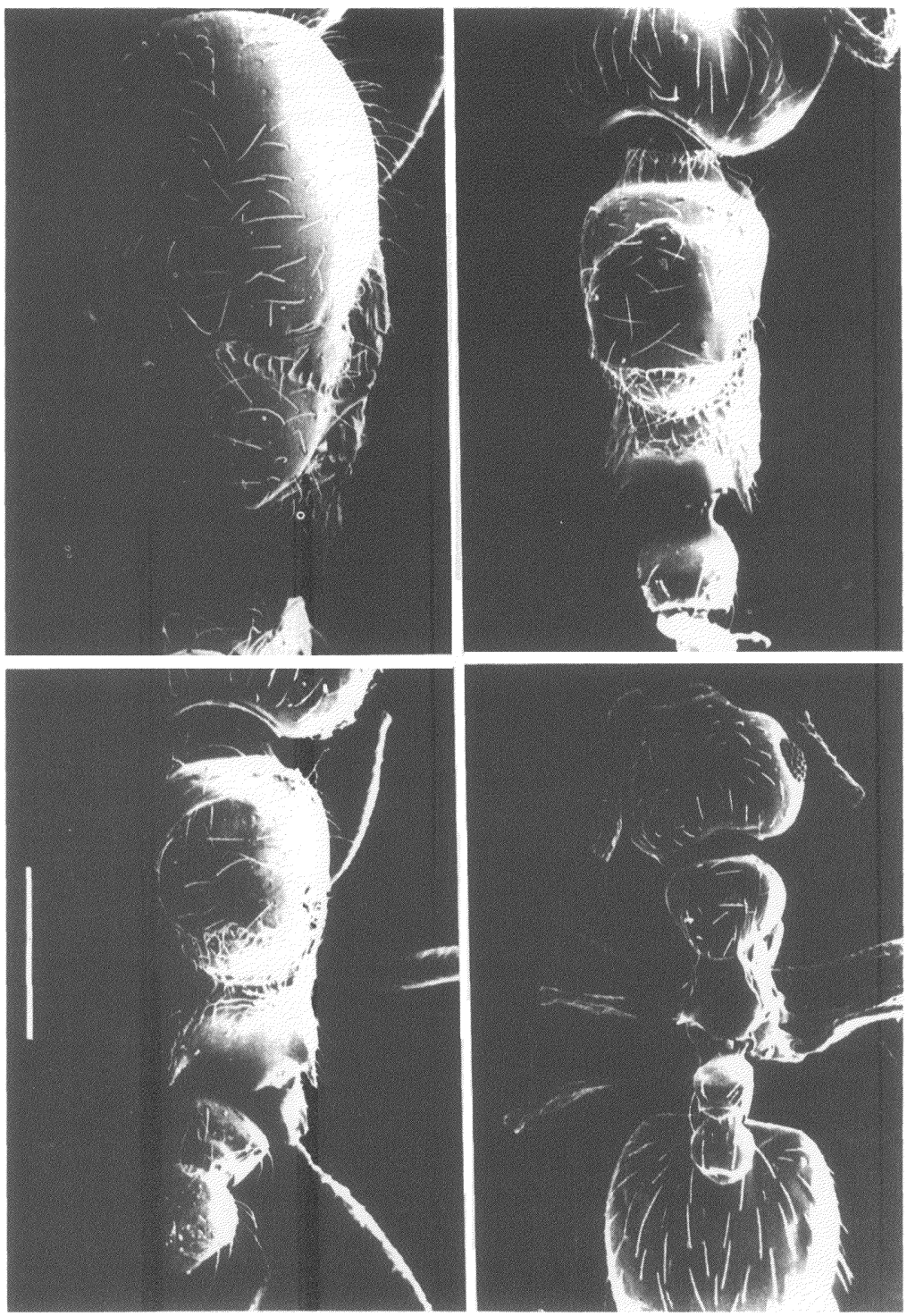

Fig. 1. Scanning electron micrographs of the alitrunk of a queen (upper left), the alitrunk and parts of the head, petiole and postpetiole of two "large workers" (upper right and lower left) and the almost complete body of a small worker (lower right) of the ant, Crematogaster smithi (all in dorsal view). The bar equals $0.5 \mathrm{~mm}$. The alitrunk of "large workers" shows an intermediate development of thoracic sclerites. 
Table 2. Approximate time budget of the three female castes in the ant $\mathrm{Cre}$ matogaster smithi. Queens and "large workers" of two colonies were observed in individual observation sessions of ten minutes each, during which the exact duration of all acts was recorded. The behavior of small workers was similarly analyzed, however, the focus animal differed between individual observation sessions to cover the behavioral repertoire of as many workers as possible. A video-analysis of approximately 100 additional hours, during which the behavioral status of individuals was recorded in irregular time intervals, supports the data from the time budget study. The category "feeding" includes both the offering of food (in "large workers" and queens, see text for details) and actual trophallaxis (in small workers). "Other activities" include cleaning the nest, feeding on honey or eggs, food begging, defecation, and egg laying. Several workers repeatedly bit the gaster tip of queen 2 , which contributes to its high score in "other activities." During the total observation period, only queen 2 laid one egg.

\begin{tabular}{|c|c|c|c|c|c|}
\hline & \multicolumn{2}{|c|}{ queen } & \multicolumn{2}{|c|}{ "large worker" } & \multirow[t]{2}{*}{ small workers } \\
\hline & 1 & 2 & 1 & 2 & \\
\hline moving & 0.120 & 0.145 & 0.096 & 0.342 & 0.133 \\
\hline resting & 0.430 & 0.408 & 0.801 & 0.391 & 0.649 \\
\hline selfgrooming & 0.001 & 0.000 & 0.002 & 0.044 & 0.059 \\
\hline outside nest & 0.000 & 0.000 & 0.000 & 0.000 & 0.004 \\
\hline grooming & 0.000 & 0.000 & 0.000 & 0.000 & 0.072 \\
\hline being groomed & 0.440 & 0.288 & 0.098 & 0.121 & 0.001 \\
\hline feeding & 0.000 & 0.001 & 0.000 & 0.025 & 0.008 \\
\hline being fed & 0.000 & 0.000 & 0.000 & 0.011 & 0.003 \\
\hline brood care & 0.000 & 0.001 & 0.000 & 0.017 & 0.033 \\
\hline antennation & 0.001 & 0.114 & 0.003 & 0.037 & 0.028 \\
\hline other activities & 0.008 & 0.043 & 0.000 & 0.012 & 0.012 \\
\hline observation time (h) & 3 & 5 & 4 & 6.5 & 8 \\
\hline
\end{tabular}

two-tailed Mann-Whitney U-test, $\mathrm{z}=0.38, \mathrm{p}>0.1$ ). So it appears that "large workers" do not serve as food storage containers for colonies. When the colony was disturbed, e.g., by removal of the cover slip covering the nest ( 30 observations), several small workers left the nest and attacked the "enemy," whereas "large workers" and the queen tried to escape. Thus "large workers" do not appear to be a defensive caste.

Both "large workers" and small workers laid eggs in queenright and in queenless colonies. Egg size varied from 0.38 to $0.58 \mathrm{~mm}$ (maximal diameter). Egg size distribution did not differ between the three female castes (Fig. 2, Mann-Whitney U-test, "large workers" vs. workers: $\mathrm{z}=-1.38, \mathrm{p}>0.1$; "large workers" vs. queens: $\mathrm{z}=-0.69, \mathrm{p}>0.9$; workers vs. queens: $\mathrm{z}=-1.24, \mathrm{p}>0.2)$. The smallest eggs, with a maximal length of less than $0.4 \mathrm{~mm}$, were flaccid and failed to embryonate when isolated. They were apparently 


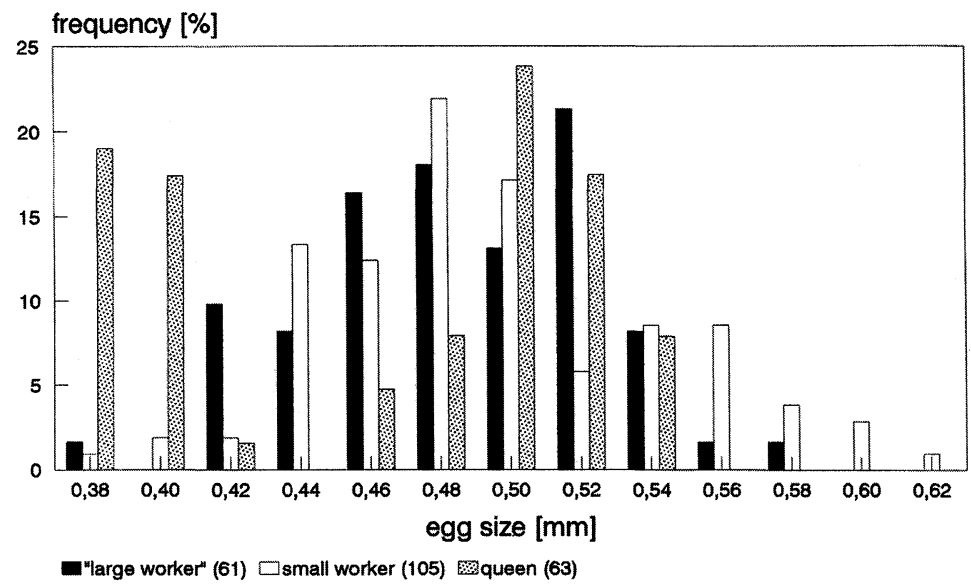

Fig. 2. Size distribution of eggs laid by "large workers," workers, and queens of Crematogaster smithi. The number of eggs measured is given in brackets.

trophic eggs. Surprisingly, the percentage of these smallest eggs was significantly larger in queens (12 of a total of 63 eggs) than in "large workers" ( 1 of 61$)$ and workers (3 of 105) ( $\chi^{2}$-Test with Yates Correction: "large workers" vs. queens: $\chi^{2}=6.59, \mathrm{p}=0.01$, workers vs. queens: $\chi^{2}=8.6, p=0.02$ ). Queens were observed laying small flaccid eggs not only in isolation but also in the colony.

The fecundity of "large workers" was extraordinarily high compared to that of small workers: during 72 hours, isolated individual queens laid 20-51 eggs, individual "large workers" laid 0-20 and groups of 50 small workers laid 0-18 eggs (Table 1). Thus, "large workers" laid significantly more eggs than small workers (twotailed Mann-Whitney U-test, $\mathrm{z}=2.3, \mathrm{p}<0.05$ ). In isolation, "large workers" from queenless colonies laid significantly more eggs than "large workers" from queenright colonies (queenless: $n=4,13.2 \pm$ 7.27; queenright: $\mathrm{n}=9,3.3 \pm 3.87 \mathrm{SD}$; two-tailed Mann-Whitney $\mathrm{U}$-test, $\mathrm{U}=3.5, \mathrm{p}<0.05$.

According to their size, most of the eggs laid by "large workers" and small workers were viable, nevertheless, many of these eggs were eaten. During 80 hours of video observations, queens ate at least 14 eggs. By reversing the video tapes, three large- and medium-sized eggs could be traced back to the moment of egg laying; two eggs had been laid by small workers about 50 minutes 
before they were eaten, and one egg had been laid by a "large worker" $19 \mathrm{~min}$. before. Both trophic and viable eggs were regularly eaten also by larvae, which apparently were not fed any other solid food items.

In 11 queenless colonies, consisting of 50 small workers each, fresh eggs appeared within two or three days and gave rise to adult males after approximately ten months. By feeding "large workers" with a fat soluble dye (Fat Red 7B) we were able to discriminate between eggs laid by "large workers" and small workers. In two queenless colonies, each with a single "large worker" and 75 or 30 small workers, respectively, the "large workers" produced $50 \%$ and $80 \%$ of all eggs. The presence of dye in the crops of five small workers in these colonies suggested that they had eaten stained eggs laid by a "large worker." When "large workers" were added to two small queenless colony fragments, in which no eggs had been laid over a period of two weeks, eggs appeared on the first day of the experiment. These two colonies also produced adult males after ten months.

Egg staining experiments did not clarify whether "large workers" produce males in queenright colonies. Firstly, as eggs were eaten by larvae, dyes were horizontally transferred to larvae which were not offspring of the mother who had been fed the dye. Secondly, stains became diluted with larval growth and were no longer visible in medium-sized or large larvae. Finally, all adults treated with fat soluble dyes died within a few weeks, probably due to toxic effects of Fat Red. Colonies with a queen, but without "large workers" also produced males.

\section{Discussion}

Colonies of the ant, Crematogaster smithi regularly contain a small number of "large workers" with a distinct morphology intermediate between queens and normal workers. According to our study, "large workers" store neither liquids in the crop as food reserve for adult workers, as in "honeypot ants" (Rissing, 1984; Hölldobler and Wilson, 1990), nor fat, as in Pheidole (Tsuji, 1990) or Colobopsis (Hasegawa, 1993). Furthermore, due to the small number of "large workers" per colony, a role in colony defense appears very unlikely. In contrast, our data suggest that "large workers" of $C$. smithi are specialized for the production of viable, 
unfertilized eggs. It cannot be completely excluded, however, that they serve an additional function in the field which could not be released under laboratory conditions.

Two lines of evidence support our conclusion: first, "large workers" almost never engaged in maintenance tasks in the colony but laid considerable numbers of eggs, and secondly, due to the anatomy of their ovaries, "large workers" are by far more fecund than small workers. The production of unfertilized eggs by workers is a common phenomenon in social insects (Bourke, 1988a; Choe, 1988), but typically individuals are not functionally and morphologically specialized for this task. In worker-polymorphic species, worker reproduction may be correlated with worker size: thus, in Messor capitatus (Delage-Darchen, 1974), Camponotus aethiops (Dartigues and Passera, 1979), Cataglyphis cursor (Cagniant, 1983), and Myrmecia froggatti (Ito, Sugiura, and Higashi, 1994), "minor" workers have a lower number of ovarioles than "major" workers and fecundity increases with worker size. In several Camponotus species, minor workers appear to be incapable of laying eggs (Bier, 1953; Benois, 1972). However, "major" workers typically perform other tasks in addition to egg laying, such as guarding or foraging in Camponotus or milling of seeds in Messor (Hölldobler and Wilson, 1990), and reproduction is not their major function. Ito et al. (1994) suggested that the large workers of Myrmecia froggatti function as a trophic caste by laying trophic eggs; however, behavioral observations confirming this hypothesis were not made. "Intercastes," morphologically intermediate between queens and workers, are known from several ant species, but they either have a spermatheca, mate and serve as the ordinary or supplementary reproductives of a colony ("reproductive intercastes," Peeters, 1991 or "intermorphic queens," e.g., Heinze and Buschinger, 1989), or do not have a special reproductive function and behave as ordinary ant workers. The combination of a distinct morphology and apparent behavioral specialization, as in the "large workers" of Crematogaster smithi, is thus unknown from other ant species. Holliday (1903) reported on morphologically intermediate "ergatoids" in a closely related species, Crematogaster minutissima. According to Fig. J in Holliday (1903), these "ergatoids" are morphologically very similar to the "large workers" of C. smithi. Whether they are functionally specialized for egg 
production is not known-dissected workers and "ergatoids" of $C$. minutissima invariably had two undeveloped ovarioles, whereas the queens had four developed ovarioles.

According to our observations, most of the eggs laid by both small and "large" workers of Crematogaster smithi are eaten in queenright colonies. It is currently unknown whether "large workers" contribute to male production in queenright colonies, and if they do so, what proportion of males do they produce. Answering this question requires distinguishing between worker- and queenproduced males-which is difficult enough but will eventually become possible with the development of highly variable genetic markers for this genus (see, e.g., Evans, 1993). As small workers may also lay eggs in queenright colonies, it will be necessary in addition to distinguish between the offspring of several hundred, closely related mothers, which is not possible at the moment. In queenless colonies, however, "large workers" apparently contribute considerably to the exclusively male progeny.

Worker male production may result in reproductive conflicts both between queens and workers and among workers (Trivers and Hare, 1976; Ratnieks, 1988; Ratnieks and Reeve, 1992). If small workers were on average more closely related to worker-produced males than to the queen's male offspring, kin selection might favor the evolution of a highly fertile caste specialized on the production of males. In contrast, queens should generally oppose worker reproduction, and in most species they appear indeed to be capable of minimizing egg laying by workers: queens may attack workers with developed ovaries (Franks and Scovell, 1983) or eat freshly laid eggs (e.g., Bourke, 1991), or workers may respond to queen pheromones by refraining from reproduction (Bier, 1954; Passera, 1980; Hölldobler and Wilson, 1983; Keller and Nonacs, 1993). Aggressive interactions among the queen and "large workers" were not observed; however, it is suggestive that egg laying rates of "large workers" were significantly lower in queenright than in queenless colonies. After the queen's death, "large workers" could produce a large, last burst of males before all the colony members die, thus increasing the inclusive fitness of all individuals.

If our laboratory observations reflect conditions in the field, "large workers" probably serve primarily as a source of eggs as food for the queen and larvae in queenright colonies, especially 
since larvae are not fed with pieces of solid prey in this species. Eggs appear to be the major protein source of larvae and perhaps also of the $C$. smithi queen. Similarly, in the closely related species C. minutissima, worker-larva trophallaxis is infrequent and larvae frequently feed on eggs (Cassill and Tschinkel, 1996). "Large workers" of $C$. smithi lay approximately 20 times more eggs per unit of weight than small workers. In contrast to most prey, eggs can be easily stored over several days. "Large workers" might thus be a reliable source of high quality protein food for the queen and the brood that is available in periods of prey shortage (Crespi, 1992; Wheeler, 1994). C. smithi lives in arid, strongly seasonal habitats which also support species of Myrmecocystus, Ephebomyrmex, and Pogonomyrmex, genera well-known for their storage economy (Hölldobler and Wilson, 1990). To have a durable supply of protein food for larvae might counterbalance potential costs inflicted on the queen by the occasional production of males by "large workers" in queenright colonies. The "large workers" themselves might benefit from laying eggs even if these are cannibalized by larvae, as this is an efficient means of investing in close relatives (Crespi, 1992). In colonies which have lost the queen, male production by highly efficient "large workers" might increase the inclusive fitness of all individuals.

\section{ACKNOWLEDGEMENTS}

This study was in part financially supported by the Deutsche Forschungsgemeinschaft (Heisenberg-scholarship He 1623/6-1 and a travel grant to JH, Leibniz-Prize to BH, and SFB 251). The Southwestern Research Station of the American Museum of Natural History provided lodging and laboratory facilities during the field excursions. K. Schilder and S. Kauffmann helped collect colonies, S. Trenkle, N. Pavlovic, and I. Percin took part in behavioral observations and morphometry. Thanks are also due to A.F.G. Bourke (London), L. Keller (Bern), P. Nonacs (Davis), F.L.W. Ratnieks (Sheffield), K. Tsuji (Würzburg), and E.O. Wilson (Cambridge, Mass.) for helpful discussions and/or comments on earlier drafts of the manuscript. 


\section{Literature Cited}

Benois, A. 1972. Evolution du couvain et cycle annuel de Camponotus vagus Scop. (= pubescens Fabr.) (Hymenoptera, Formicidae) dans la région d'Antibes. Ann. Zool. Écol. anim. 4:325-351.

Bier, K. 1953. Vergleichende Untersuchungen zur Fertilität der Ameisenarbeiterinnen. Zool. Anz. 150:282-288.

Bier, K. 1954. Über den Einflu $\beta$ der Königin auf die Arbeiterinnenfertilität im Ameisenstaat. Ins. Soc. 1:7-19.

Bourke, A.F.G. 1988a. Worker reproduction in the higher eusocial Hymenoptera. Quart. Rev. Biol. 63:291-311.

1988b. Dominance orders, worker reproduction and queen-worker conflict in the slave-making ant Harpagoxenus sublaevis. Behav. Ecol. Sociobiol. 23:323-333.

1991. Queen behaviour, reproduction and egg-cannibalism in multiplequeen colonies of the ant Leptothorax acervorum. Anim. Behav. 42:295-310.

Cagniant, H. 1983. La parthénogenèse thélytoque et arrhénotoque des ouvrières de la fourmi Cataglyphis cursor Fonscolombe, Hymenoptères Formicidae). Étude biométrique des ouvrières et de leurs potentialités reproductrices. Ins. Soc. 30:241-254.

Cassill, D.L., and W.R. Tschinkel. 1996. A duration constant for worker-to-larvae trophallaxis in fire ants. Ins. Soc. 43:149-166.

Choe, J.C. 1988. Worker reproduction and social evolution in ants (Hymenoptera, Formicidae). In: Advances in Myrmecology (Ed. J.C. Trager), Brill, Leiden, 163-187.

Creighton, W.S. 1950. The ants of North America. Bull. Mus. Comp. Zool. 104:1-585.

Cole, B.J. 1981. Dominance hierarchies in Leptothorax ants. Science 212:83-84.

Crespi, B.J. 1992. Cannibalism and trophic eggs in subsocial and eusocial insects. In: Cannibalism: Ecology and Evolution among Diverse Taxa (Eds. M.A. Elgar, and B.J. Crespi), Oxford Univ. Press, Oxford, 176-213.

Dartigues, D., and L. Passera. 1979. La ponte des ouvrières chez la fourmi Camponotus aethiops Latreille (Hym. Formicidae). Annls. Soc. ent. Fr. (N.S.) 15:109-116.

Dejean, A. and L. Passera. 1974. Ponte des ouvrières et inhibition royale chez la fourmi Temnothorax recedens (Nyl.) (Formicidae, Myrmicinae). Ins. Soc. 21:343-356.

Delage-Darchen, B. 1974. Polymorphismus in der Ameisengattung Messor and ein Vergleich mit Pheidole. In: Sozialpolymorphismus bei Insekten (Ed. G.H. Schmidt), Wiss. Verlagsges, mbH, Stuttgart, 590-603.

Evans, J.D. 1993. Parentage analyses in ant colonies using simple sequence repeat loci. Mol. Ecol. 2:393-397.

Franks, N.R., and E. Scovell. 1983, Dominance and reproductive success among slave-making worker ants. Nature 304:724-725.

Hasegawa, E. 1993. Caste specialization in food storage in the dimorphic ant Colobopsis nipponicus (Wheeler). Ins. Soc. 40:261-271.

Heinze, J., and A. Buschinger. 1989. Queen polymorphism in Leptothorax spec. A: its genetic and ecological background (Hymenoptera: Formicidae). Ins. soc. 36:139-155. 
Heinze, J., B. Hölldobler, and C. Peeters. 1994. Conflict and cooperation in ant societies. Naturwissenschaften 81:489-497.

Hölldobler, B., and E.O. Wilson. 1983. Queen control in colonies of weaver ants (Hymenoptera: Formicidae). Ann. Entomol. Soc. Am. 76:235-238.

1990. The Ants. The Belknap Press of Harvard University Press, Cambridge, Mass. 732p.

Holliday, M. 1903. A study of some ergatogynic ants. Zool. Jb. Abt. Syst. Ökol. Geogr. Tiere 19:293-328.

Ito, F., N. Sugiura, and S. Higashi. 1994. Worker polymorphism in the red-headed bulldog ant (Hymenoptera: Formicidae), with description of nest structure and colony composition. Ann. Entomol. Soc. Am. 87:337-341.

Keller, L., and P. Nonacs. 1993. The role of queen pheromones in social insects; queen control, or queen signal. Anim. Behav. 45:787-794.

Oliveira, P.S., and B. Hölldobler. 1990. Dominance orders in the ponerine ant Pachycondyla apicalis (Hymenoptera: Formicidae). Behav. Ecol. Sociobiol. 287:385-393.

Passera, L. 1980. La fonction inhibitrice des reines de la fourmi Plagiolepis pygmaea Latr.: rôle des pheromones. Ins. Soc. 27:212-225.

Peeters, C. 1991. Ergatoid queens and intercastes in ants: two distinct forms which look morphologically intermediate between workers and winged queens. Ins. soc. 38:1-15.

Peeters, C., and K. Tsuji. 1993. Reproductive conflict among ant workers in Diacamma sp. from Japan: Dominance and oviposition in the absence of the gamergate. Ins. Soc. 40:119-136.

Ratnieks, F.L.W. 1988. Reproductive harmony via mutual policing by workers in eusocial Hymenoptera. Am. Nat. 132:217-236.

Ratnieks, F.L.W., and H.K. Reeve. 1992. Conflict in single-queen hymenopteran societies: the structure of conflict and processes that reduce conflict in advanced eusocial species. J. theor. Biol. 158:33-65.

Rissing, S.W. 1984. Replete caste production and allometry of workers in the honey ant, Myrmecocystus mexicanus Wesmael (Hymenoptera: Formicidae). J. Kansas Entomol. Soc. 57:347-350.

Sendova-Franks, A., and N.R. Franks. 1993. Task allocation in ant colonies within variable environments (a study of temporal polyethism: experimental). Bull. Math. Biol. 55:75-96.

Soulié, J. 1970. Des considérations écologiques peuvent-elles apporter une contribution à la connaissance du cycle biologique des colonies de Crematogaster (Hymenoptera-Fornicoidea)? Ins. Soc. 7:283-295.

Trivers, R.L., and H. Hare. 1976. Haplodiploidy and the evolution of the social insects. Science 191:249-263.

Tsuji, K. 1990. Nutrient storage in the major workers of Pheidole ryukywensis (Hymenoptera: Formicidae). Appl. Ent. Zool. 25:283-287.

Torossian, C. 1978. La ponte d'oeufs abortifs chez les ouvrières de la fourmi Dolichoderus quadripunctatus. Bull. Soc. Hist. Nat. Toulouse 114:207-211.

Wheeler, D.E. 1994. Nourishment in ants: patterns in individuals and societies. In: Nourishment and evolution in insect societies (Eds. J. Hunt and C. Nalepa), Westview Press, Boulder, 245-278.

Wilson, E.O. 1971. The Insect Societies. The Belknap Press of Harvard University Press, Cambridge, Mass. 548p.

Wilson, E.O. 1985. The sociogenesis of insect colonies. Science 228:1489-1495. 

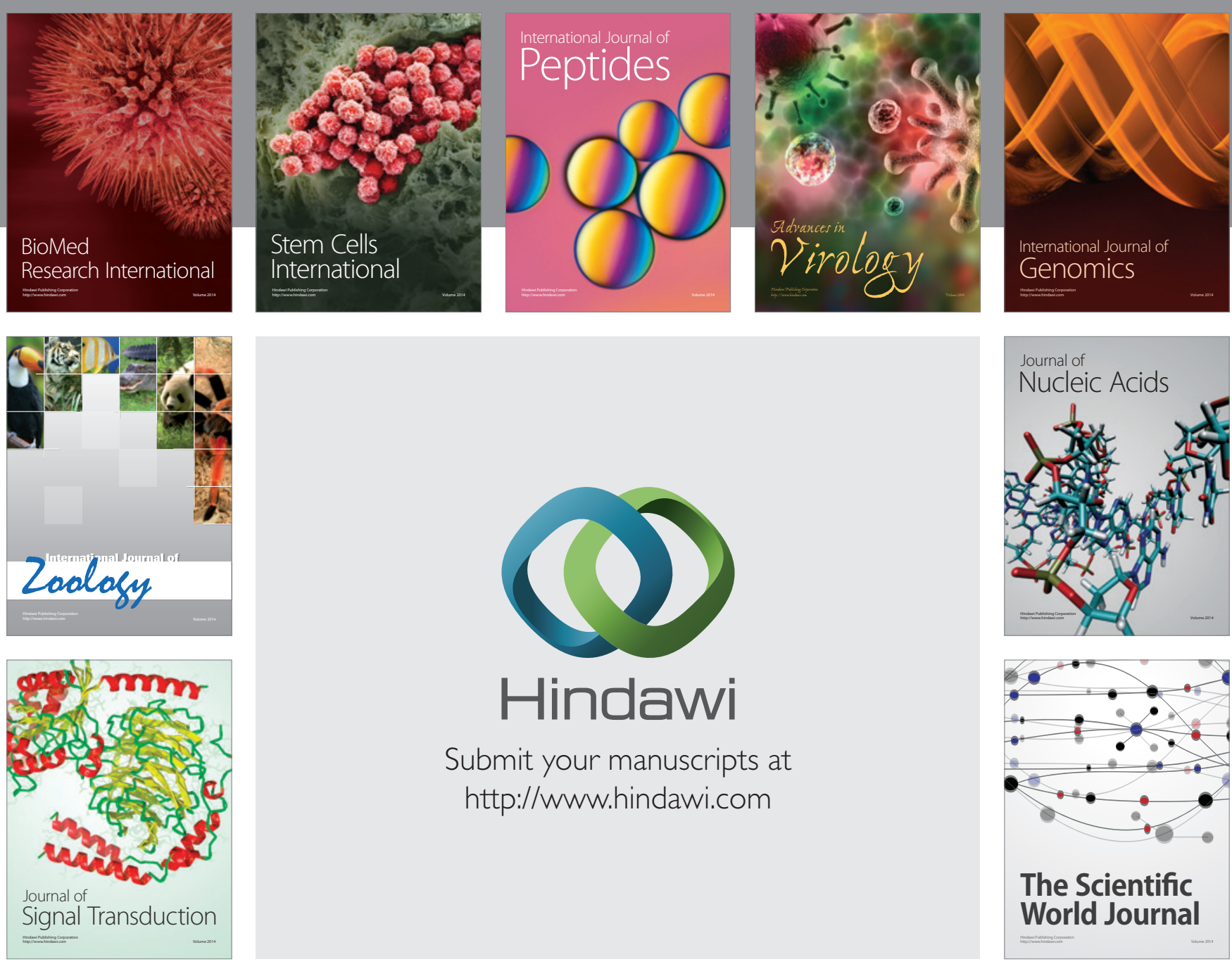

Submit your manuscripts at

http://www.hindawi.com
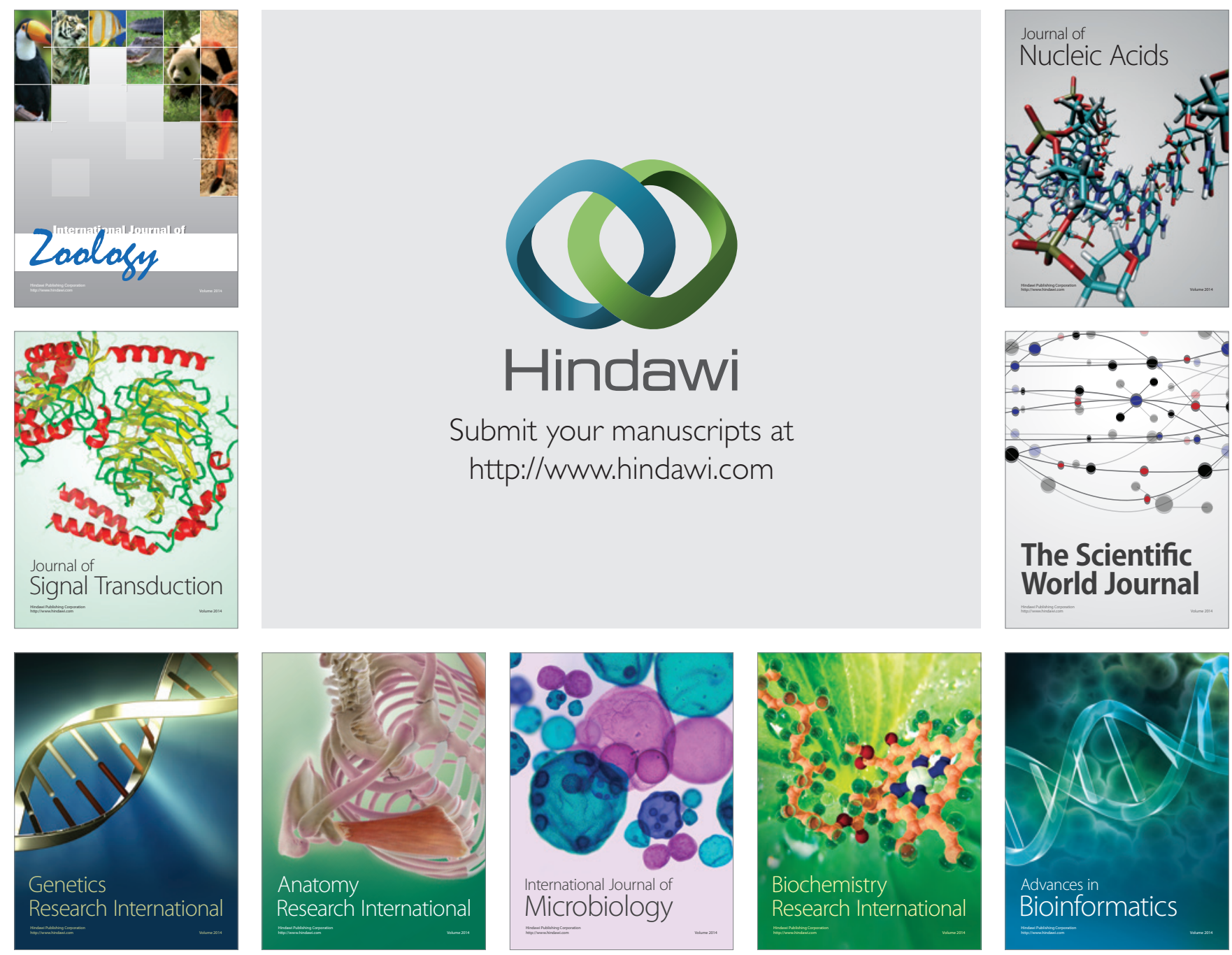

The Scientific World Journal
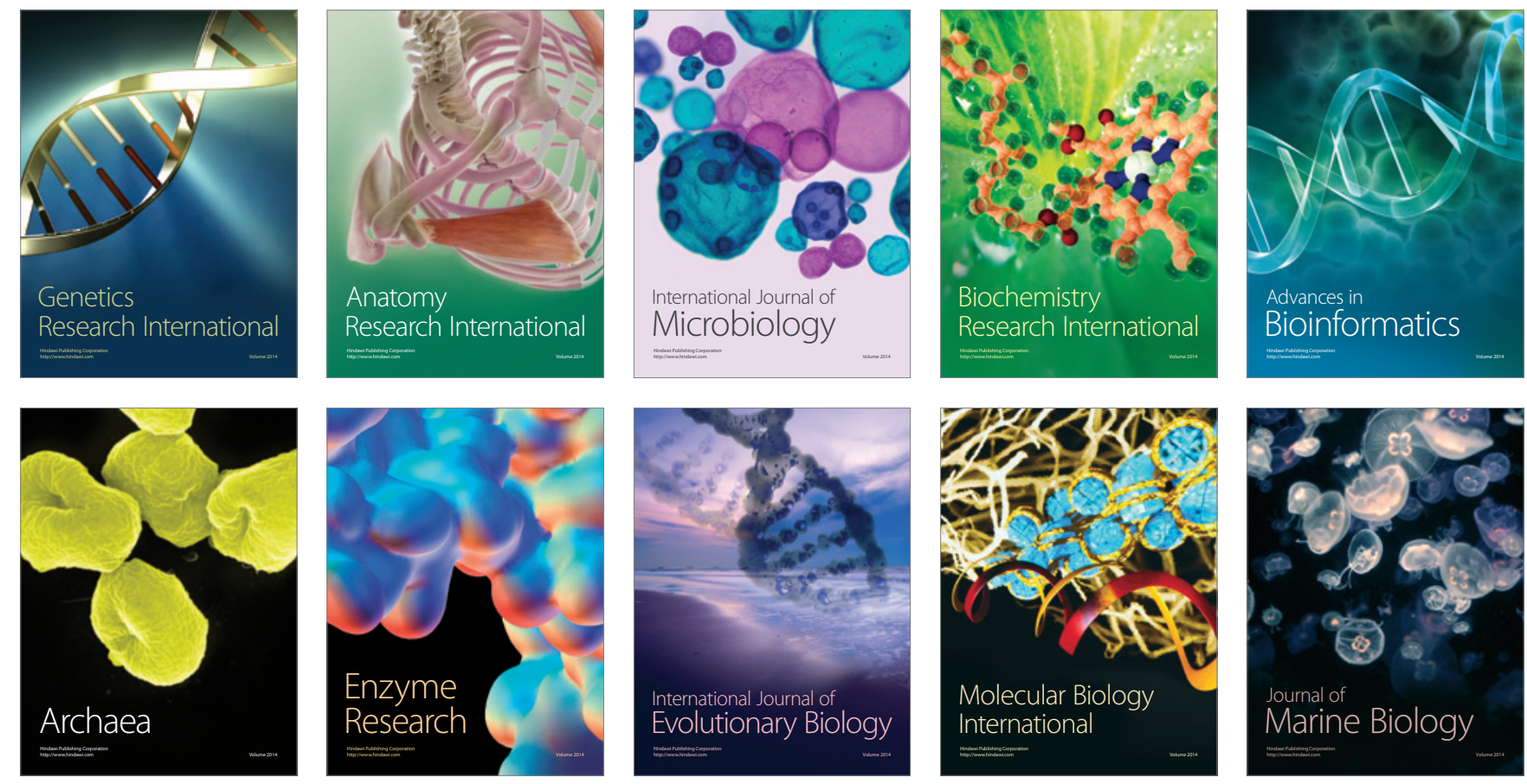